\title{
Utility of paperless partogram in labor management
}

\author{
Nazli Tarannum*, Nishat Akhtar \\ Department of Obstetrics and Gynecology, Jawaharlal Nehru Medical College and Hospital, Aligarh Muslim
} University, Aligarh, Uttar Pradesh, India

Received: 09 December 2019

Revised: 31 December 2019

Accepted: 04 January 2019

\section{*Correspondence: \\ Dr. Nazli Tarannum, \\ E-mail: nazlinator@gmail.com}

Copyright: (c) the author(s), publisher and licensee Medip Academy. This is an open-access article distributed under the terms of the Creative Commons Attribution Non-Commercial License, which permits unrestricted non-commercial use, distribution, and reproduction in any medium, provided the original work is properly cited.

\section{ABSTRACT}

Background: Partograph use in labor has revolutionized the obstetric care. WHO recommends universal use of WHO modified partograph, which in clinical setup is less often used. Debdas (2006) proposed the paperless partogram which is designed for use by clinician/nurses/midwives as it is very simple and low skill method. The present study is proposed to evaluate the effectiveness of paperless partogram as a bedside tool and its comparison with WHO modified partograph.

Methods: It was a prospective analytical study done in department of obstetrics and gynecology, JNMCH, AMU, Aligarh from September 2017 to July 2019 and included 400 pregnant women at term, divided into 2 groups of 100 each Group A (paperless partogram) and Group B (WHO modified partograph) and their labor events were followed.

Results: Out of 200 women that were included in each group, maximum women were multigravida, $58.5 \%$ in group A and $61.5 \%$ women in Group B. Mean age in Group A was 24.68 \pm 3.8 years and Group B was 24.93 \pm 3.75 years. The

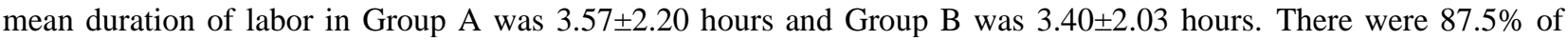
women who delivered before alert ETD, likewise in Group B; women who delivered before alert line are $88.5 \%$. These differences were statically not significant. Perinatal outcome was also similar in both groups.

Conclusions: In our study, the paperless study was found to be as efficient as WHO modified partograph for management of labor. The mean delivery time was 3.57 hours similar to WHO partograph of difference between alert and action line. Thus, for resource poor setting like India with overburdened population paperless partogram can be used as an alternative to WHO modified partograph which is complex and time consuming.

Keywords: Alert estimated time of delivery, Management of labor, Paperless partogram

\section{INTRODUCTION}

Maternal mortality continues to be a major public health problem worldwide. India is among those countries which has a very high maternal mortality rate (MMR). ${ }^{1}$ Programmes catering maternal health in India have reduced MMR from 556/1 lakh live births in 1990 to $174 / 1$ lakh live births in 2015, which is a substantial change of $68.7 \%$ but yet this figure is very high as compared to other developed countries. ${ }^{2}$ One of the major causes of maternal death include prolonged and obstructed labor (10\%) leading to perinatal and maternal morbidity and mortality. ${ }^{4}$ Continuous monitoring of labor and timely intervention thus plays an important role in improving the obstetrical and perinatal outcome.

Partograph use in labour has revolutionized the obstetric care. Friedman in 1954 introduced the concept of partogram by depicting the dilatation of cervix graphically which was later modified by Philpot and Castle in 1972. ${ }^{3}$ They included alert and action lines besides cervicogram. ${ }^{4}$ WHO modified it further (2001) 
where the latent phase was removed and active phase was plotted at $4 \mathrm{~cm}$ dilatation. ${ }^{5,6}$

WHO modified partograph is an inexpensive pictorial tool which provides the overview of labor on a single sheet. Studies have shown that it is highly effective in reducing complications by timely prediction of abnormal labor and thus providing enough time for early intervention in terms of augmentation, caesarean section and timely referral to higher centre. ${ }^{7,8} \mathrm{WHO}$ recommends universal use of WHO modified partograph, which in clinical setup is less often used and when used it is incompletely interpreted. Dr. Debdas argued that WHO partograph has not been adapted to local needs, accepted to those who use it and cannot be used given available resource. ${ }^{9,10}$ There are many factors that seem to be responsible for non-compliance of partograph use which includes - lack of awareness, lack of availability, negative perceptions of partograph, high patient load, less clinician, extra time to plot data. ${ }^{11-14}$ Similar observations were made by Qureshi and Margaret and they also concluded that shortage of staff and complex face of the graph was the major causes of poor compliance. ${ }^{15,16}$ These drawbacks highlighted the need for development of a new tool for labor monitoring which is suitable for poor resource setting like India and can also be used at community level.

Debdas proposed the paperless partogram which is designed for use by clinician/nurses as it is very simple and low skill method. It is a two-step calculation with basic addition and no graph paper and no extra time needed. The monitoring is based on calculation of an alert ETD (estimated time of delivery) and action ETD based on Friedman's golden rule of cervical dilatation that cervix dilates at the rate of $1 \mathrm{~cm} /$ hour when women enters active phase of labour. ${ }^{1}$ Thus, calculation of alert ETD helps in identifying and diagnosis of abnormal labor and provides time to intervene and terminate labor or to transfer patient to higher centre with caesarean section facility. ${ }^{17}$ The present study is proposed to evaluate the effectiveness of paperless partogram as a bedside tool in comparison to WHO modified partograph in managing labor in resource poor setting.

\section{METHODS}

The study was prospective analytical study carried out in department of obstetrics and gynecology, Jawaharlal Nehru Medical College and Hospital, AMU, Aligarh from September 2017 to July 2019 and included 400 Pregnant women recruited from antenatal clinic, outdoor patient department and labor room.

\section{Inclusion criteria}

- $\quad$ Pregnant women irrespective of age and parity

- $\quad$ Singleton pregnancy

- Gestational age from 36 to 42 weeks gestation

- Cephalic presentation
- Women should be $4 \mathrm{~cm}$ or more dilated at the point of inclusion.

\section{Exclusion criteria}

- Non cephalic presentation

- Known foetal structural anomaly

- Previous c/s or uterine surgery

- Premature or post-dated pregnancy

- Maternal co morbidities/ high risk pregnancy.

Ethical clearance was obtained from the institutional ethical committee.

Participants were included only after informed and written consent.

Admitted pregnant women will be examined after taking detailed obstetrics and gynaecological history. Women fulfilling inclusion criteria will be randomly assigned to one of the 2 groups- the modified WHO partograph or paperless partogram for monitoring of labour in active phase of labour $\geq 4 \mathrm{~cm}$ of cervical dilatation.

It entails only $5 \mathrm{~min} / \mathrm{case}$.

Group A (paperless partogram)

In paperless model of study alert ETD and an action Etd was calculated.

Alert ETD: According to Friedman's rule that cervix dilates at $1 \mathrm{~cm} /$ hour: 6 hours is simply added to time at which women was $4 \mathrm{~cm}$ dilated to get Alert ETD. ${ }^{6}$

Action ETD: 4 hours are added to Alert ETD to get action ETD.

Both ETDs written in big letters on front of the case sheet and Action ETD circled in RED. Whole procedure is paperless/graph less and is done in split second mental calculation.

Alert ETD: At time of Alert ETD, if a woman has not delivered yet, clinician was alerted and sensitized. Careful monitoring and intervention done. e.g. if contractions are poor, Labor augmented by oxytocin or ARM. A mandatory PV examination done at this point of time.

Action ETD: If she has not yet delivered spontaneously by this extra 4 hours, and then she is at risk of prolonged labor and needed delivery by suitable medical or surgical technique.

The difference between alert ETD and action ETD i.e. 4 hours denotes the timing for intervention of prolonged labor. It is in accordance with WHO modified partograph recommendation where difference between alert line and 
action line is 4 hours. In WHO partograph in active phase of labor cervical dilatation will remain normally on/left of alert line. When dilatation crosses to the right of alert line it is a warning that labor might be prolonged but it does not signify obstructed labor and does not compromise feto-maternal outcome. However, when action line is crossed, it signifies that action must be taken immediately (WHO). ${ }^{18-20}$

\section{Monitoring of labor done and documented in case} sheets.

- $\quad$ FHR, liquor, contraction in 10 minutes = every $1 / 2$ hourly

- $\quad$ BP, Temperature $=1$ hourly

- PV Examination = 4 hourly to see dilation of cervix, and descent and moulding of head.

Group B (modified who partograph).

Events of labour will be followed according to WHO modified partograph.

The two groups were followed till delivery. Both maternal and fetal outcomes were documented at bottom of graph or case sheet. Details of labor included:

- Duration of labour

- Mode of delivery

- Maternal complication like prolonged labour, obstructed labour, operative interventions

- Foetal outcome like birth weight, Apgar score, NICU admission.

\section{Statistical analysis}

The data entry and analysis were performed using SPSS version 20. Descriptive frequencies, percentage, means and chart were used. Chi - Square test and student t-test statistical methods were used as appropriate and results confirmed at 0.005 level of confidence.

\section{RESULTS}

Table 1: Baseline characteristics of females.

\begin{tabular}{|l|l|l|}
\hline Variable & $\begin{array}{l}\text { Group A } \\
(\mathbf{n = 2 0 0})\end{array}$ & $\begin{array}{l}\text { Group B } \\
(\mathbf{n}=\mathbf{2 0 0})\end{array}$ \\
\hline Age (years) & $24.68 \pm 3.88$ & $24.93 \pm 3.75$ \\
\hline Gestational age (weeks) & $38.63 \pm 1.24$ & $38.71 \pm 1.25$ \\
\hline Nutritional status (BMI) & $22.8 \pm 1.4$ & $23.0 \pm 1.1$ \\
\hline
\end{tabular}

Total 400 pregnant women in labor fulfilling the inclusion criteria were recruited for the study and their labor outcome were followed using either partograph. 200 Women were included in Group A (paperless partogram) and another 200 in Group B (WHO modified partograph). The baseline characteristics of the female is as described in Table 1.
It was seen that more than $65 \%$ women in both groups were less than 25 years. Both groups however had no significant difference in age, gestational age as seen in Table 1. Out of 200 women in both group $58.5 \%$ in Group A and $61.5 \%$ in group were multigravida and the difference were not significant.

Table 2: Distribution of women in relation to alert and action ETD/line.

\begin{tabular}{|lll|}
\hline Delivery time & $\begin{array}{l}\text { Group A } \\
(\mathbf{N}=200)\end{array}$ & $\begin{array}{l}\text { Group B } \\
(\mathbf{N}=200)\end{array}$ \\
\hline $\begin{array}{l}\text { Within alert ETD/alert } \\
\text { line }\end{array}$ & $175(87.5 \%)$ & $177(88.5 \%)$ \\
\hline $\begin{array}{l}\text { Between alert ETD/ } \\
\text { alert line and action } \\
\text { ETD and action line }\end{array}$ & $19(9.5 \%)$ & $14(7 \%)$ \\
\hline $\begin{array}{l}\text { Beyond action ETD/ } \\
\text { action line }\end{array}$ & $6(3 \%)$ & $9(4.5 \%)$ \\
\hline
\end{tabular}

In our study it was seen that majority of women in both group $87.5 \%$ in Group A and $88.5 \%$ in Group B delivered before reaching the alert ETD/line as seen in Table 2. It was seen that only 3\% in Group A and $4.5 \%$ in Group B delivered beyond Action ETD/Line. Out of 200 women in both groups only 8 females in Group A and 9 females in Group B had LSCS while majority had spontaneous vaginal delivery $94 \%$ in Group A and $93.5 \%$ in Group B as seen in Table 3. The difference between both groups were not significant and $\mathrm{p}$ value is 0.90 .

Table 3: Distribution of women according to mode of delivery.

\begin{tabular}{|lll|}
\hline Mode of delivery & $\begin{array}{l}\text { Group A } \\
(\mathbf{n}=200)\end{array}$ & $\begin{array}{l}\text { Group B } \\
(\mathbf{n}=200)\end{array}$ \\
\hline $\begin{array}{l}\text { Normal vaginal delivery } \\
(\text { FTND) }\end{array}$ & $188(94 \%)$ & $187(93.5 \%)$ \\
\hline $\begin{array}{l}\text { Caesarean section } \\
\text { (LSCS) }\end{array}$ & $8(4 \%)$ & $9(4.5 \%)$ \\
\hline $\begin{array}{l}\text { Operative vaginal } \\
\text { delivery }\end{array}$ & $4(2 \%)$ & $4(2 \%)$ \\
\hline
\end{tabular}

In our study it was seen that the active phase of labor (4 $\mathrm{cm}$ to delivery) ranged from as low as 30 minutes to 11 hours in some women as shown in Figure 1. However, the mean duration of labor was 3.53 hours in Group A (paperless partogram) and 3.40 hours in Group B (WHO modified partograph) as seen in Table 4 . The $\mathrm{p}$ value was 0.54 making the difference between both group nonsignificant. It was also seen that $76 \%$ of women in Group A and $80 \%$ of women in Group B delivered within 4.30 hours indicating that majority of women delivered before alert ETD/time

On analysis of perinatal outcome in both groups, it was seen that around $70 \%$ of babies in both groups had birth weight ranging from 2.51 to $3.50 \mathrm{~kg}$. Mean baby birth weight was found to be $2.90 \mathrm{~kg}$ in Group A (paperless 
partogram) and $2.91 \mathrm{~kg}$ in Group B (WHO modified partograph) as shown in Table 5 and the $\mathrm{p}$ value between the both Group was found to be 0.81 making the difference not significant. Out of 200 babies born in both group 14 in Group A and 11 in Group B was admitted in NICU as seen in Table no 5 of which majority 6 in Group A and 5 in Group B was for low birth weight (LBW) attributed to poor nutritional status of mother.

Table 4: Total duration of labour in both groups.

\begin{tabular}{|c|c|c|c|c|}
\hline Mean duration \pm SD & Group A & Group B & $\mathbf{t}$ & p value \\
\hline (in hours) & $3.53 \pm 2.208$ & $3.40 \pm 2.030$ & 0.599 & $0.5497(\mathrm{NS})$ \\
\hline
\end{tabular}

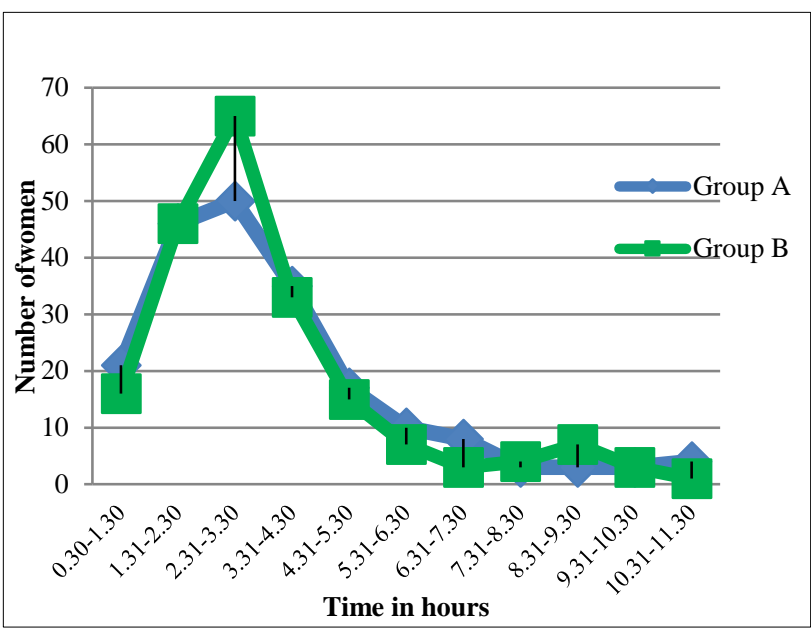

Figure 1: Distribution of women according to total duration of labour.

Table 5: Perinatal outcome in both groups.

\begin{tabular}{|llll|}
\hline Variable & $\begin{array}{l}\text { Group A } \\
(\mathbf{n}=200)\end{array}$ & $\begin{array}{l}\text { Group B } \\
(\mathbf{n}=200)\end{array}$ & p value \\
\hline $\begin{array}{l}\text { Mean } \\
\text { weight }(\mathrm{kg})\end{array}$ & $2.90 \pm 0.466$ & $2.91 \pm 0.463$ & $0.8132(\mathrm{NS})$ \\
\hline $\begin{array}{l}\text { NICU } \\
\text { admission }\end{array}$ & $14(7 \%)$ & $11(5.5 \%)$ & $0.68(\mathrm{NS})$ \\
\hline
\end{tabular}

\section{DISCUSSION}

Prolonged and obstructed labor is a preventable cause of maternal and fetal morbidity and mortality. Early decision and timely intervention and referral to higher centre serves as an efficient measure in serving the call. WHO modified partograph is a very complex, time consuming and moreover is technically demanding? In a resource poor country like India with overburdened doctors and nurses it is rarely used. Paperless partograph on the other hand is very simple, easy to learn graph less technology to monitor labor and thus is very helpful. Even ASHA and ANM can easily do so. Keeping this in mind the present study was done to see how effective is paperless partogram in monitoring labor when compared to WHO modified partograph.

In the present study we found that most patient followed normal delivery course and delivered before the estimated delivery time in both group of patients without any undue intervention needed. $87 \%$ in Group $\mathrm{A}$ and $88.5 \%$ in Group B delivered before reaching ETD. This result is similar to study done by Giri DK et al where in Group A it was $80 \%$ and Group B was $81 \% .^{21}$ Other studies with results similar were Deka G et al, where $83 \%$ in Group A delivered before ETD and 77\% in Group B delivered before alert line. ${ }^{22}$ Veena $\mathrm{L}$ et al, also saw that patient followed normal course of delivery and delivered before alert ETD in $83 \%$ in Group A and $77 \%$ in Group B. ${ }^{23}$

Most of patient i.e. $94 \%$ in Group A and $93.5 \%$ in Group $\mathrm{B}$ had spontaneous normal vaginal delivery without much intervention needed. Only 4\% in Group A and $4.5 \%$ in Group B had to undergo LSCS however none of the baby or mother was compromised. This result is similar with study conducted by Deka $G$ et al, were spontaneous vaginal delivery was found to be $88.5 \%$ in Group A and $85 \%$ in Group B women. ${ }^{22}$ Veena L et al, found that there was $85 \%$ spontaneous vaginal delivery in paperless group and $79 \%$ in women followed by WHO modified partograph. $^{23}$

Perinatal outcome were similar in both groups in terms of baby weight which was found to be $2.90 \mathrm{~kg}$ in Group A and $2.91 \mathrm{~kg}$ in Group B. this result is in concordance to study of Deka $G$ et al, where mean baby weight in paperless group was $2.7 \mathrm{~kg}$ and WHO modified partograph was also $2.7 \mathrm{~kg}{ }^{22}$

From our result we found that most patients follow a normal delivery course and both paperless partogram and WHO modified partograph was effective in management of labor and gave similar result on maternal and fetal parameter and outcome. Thus, introduction of paperless partogram for monitoring labor can be very promising as simple easy and cast effective bedside tool. It can be especially useful in low skilled setting with nurses, ANM and ASHA for managing labor diagnosing prolonged labor and timely referral to higher centre.

\section{CONCLUSION}

Obstructed labor accounts for nearly 5\% of maternal mortality in India. These can be prevented if any deviation from normal course of labor is timely diagnosed and intervened. WHO modified partograph has been time tested to track normal delivery course but 
because of its complex graph it is rarely used. Dr Debdas paperless partograph is an easy, graph less, effective alternative to WHO modified partograph to monitor the labor progress. Done easily in 20 seconds with calculation of alert and action ETD, it has potential to survive many mother and babies. Paperless partogram can be easily introduced in $\mathrm{PHC} / \mathrm{CHC} /$ nursing home with less number as well as less trained staff with no additional cost to reduce maternal and fetal morbidity and mortality and good care.

\section{Funding: No funding sources}

Conflict of interest: None declared

Ethical approval: The study was approved by the Institutional Ethics Committee

\section{REFERENCES}

1. World Health Organization. Trends in maternal mortality: 1990 to 2015: estimate by WHO, UNICEF, UNFPA, World Bank Group and the United Nations Population Division. Geneva: World Health Organisation; 2015.

2. World Health Organization. 2014. Trends in Maternal Mortality: 1990 to 2013 - estimates by WHO, UNICEF, UNFPA, The World Bank and the United Nations. Population Division. World Health Organization.

3. Friedman E. Graphic analysis of labor. Am J Obstet Gynecol. 1954;68:1568-75.

4. Philpott RH, Castle WM. Cervicographs in the management of labour in primigravidae. J Obstet Gynaecol Br Common. 1972;79:592-8.

5. Dujardin B, De Schampheleire I, Kurker R, Bailey J. The partograph: is it worth including the latent phase. Trop Doct. 1995;25(1):43-4.

6. World Health Organization. World Health Organization partogram in the management of Labour. Lancet. 1994;343:1399-404.

7. Roy D, Mandal D, Sahana RK, Mandal A, Chowdhury P, Kundu P. ETD-expected time of delivery: a new simple clinical tool for management of labour. AICOG Patna. 2014;2.

8. Pujar KG, Salian SV, Kulkarni SR. Partographic analysis of labour by modified who partograph in primigavidae: a prospective observational study. Int $\mathrm{J}$ Reprod Contracept Obstet Gynecol. 2016;5:166-9.

9. Debdas AK, Singh V. Role of partogram in indian scenario, obgyn highlights-an evidence-based review, Ed Chatterjee, A and Das Mahapatra P, jointly published by AICC-RCOG, Eastern Zone and Ministry of Health and Family Welfare, Govt of India, on the occasion of $21^{\text {st }}$ AICC RCOG Conference, Kolkata. 2006:37-44.

10. Debdas AK. Paperless Partogram. 41 ${ }^{\text {st }}$ Annual Scientific Session 2008; Sri Lanka Coll Obstet Gynaecol SLJOG. 2008;1(1):124.
11. Kawuwa MB, Mairiga AG, Usman HA. Maternal mortality: Barriers to care at the health facility- Health workers perspective. J Obstet Gynaecol. 2009;26(6):544-5.

12. Dujardin B, De Schampheleire I, Sene H, Ndiaye F. Value of the alert and action lines on the partogram. Lancet. 1992;339:1336-8.

13. Fawole AO, Hunyinbo KI, Adekunle DA. Knowledge and utilization of the partograph among obstetric care givers in South West Nigeria. Af J Reprod Health. 2010;12(1):22-9.

14. Oladapo OT, Daniel OJ, Olatunji AO. Knowledge and use of the partograph among health care personnel at the peripheral maternity centers in Nigeria. J Obstet Gynaecol. 2008;26(6):538-41.

15. Qureshi ZP, Sekadde-Kigondu C, Mutiso SM. Advanced obstertrics nursing: partograph utilisation. East African. 2010:123-9.

16. Opiah MM, Abosede Bola OF, Essien EJ, Monjok E. Knowledge and utilization of the partograph among midwives in the Niger Delta Region Nigeria. Af $\mathbf{J}$ Reprod Health. 2012;16(1):125-32.

17. Elizabeth A. The Paperless Partogram: A Simplified Tool to Prevent Prolonged Labor. Available at: http://www.healthynewbornnetwork.org/blog/paper less-partogramsimplified-tool-prevent-prolonged-labor. Accessed on 2012 e 28.

18. WHO partograph cuts complications of labor and childbirth? Safe Mother. 1994;(15):10.

19. Mathews JE, Rajaratnam A, George A, Mathai M. Comparison of two World Health Organization (WHO) partographs. Int J Gynecol Obstet. 2007;96(2):147-50.

20. Mathai, Matthews. The partograph for the prevention of obstructed labor. Clin Obstet Gynecol. 2009;52(2):25669.

21. Giri DK, Nayak L, Dala DK. Comparison of procedure and predictability between WHO partogram and paperless partogram. JMSCR. 2019;7(7):611-4.

22. Deka G, Sharma R, Das GC.The paperless partographcan it be effective to replace the WHO modified partograph. Int J Reprod Contracept Obstet Gynecol. 2016;5:452-5.

23. Veena L, Sarojini, Anagondanahalli P, Prakash, Suchitra. Study to compare between paperless partogram and modified who partogram in management of labour. Int J Reprod Contracept Obstet Gynecol. 2018;7:99-103.

Cite this article as: Tarannum N, Akhtar N. Utility of paperless partogram in labor management. Int $\mathbf{J}$ Reprod Contracept Obstet Gynecol 2020;9:1045-9. 